\title{
Nanospider Technology for the Production of Nylon-6 Nanofibers for Biomedical Applications
}

\author{
Mohamed H. El-Newehy, ${ }^{1,2}$ Salem S. Al-Deyab, ${ }^{1}$ El-Refaie Kenawy, ${ }^{2}$ \\ and Ahmed Abdel-Megeed ${ }^{3,4}$ \\ ${ }^{1}$ Petrochemical Research Chair, Department of Chemistry, College of Science, King Saud University, \\ P.O. Box 2455, Riyadh 11451, Saudi Arabia \\ ${ }^{2}$ Polymer Research Group, Department of Chemistry, Faculty of Science, Tanta University, Tanta 31527, Egypt \\ ${ }^{3}$ Department of Botany, College of Science, King Saud University, P.O. Box 2455, Riyadh 11451, Saudi Arabia \\ ${ }^{4}$ Department of Plant Protection, Faculty of Agriculture (Saba Basha), Alexandria University, Alexandria 21513, Egypt
}

Correspondence should be addressed to Mohamed H. El-Newehy, mnewehy@hotmail.com

Received 4 December 2010; Accepted 15 February 2011

Academic Editor: Bohua Sun

Copyright (C) 2011 Mohamed H. El-Newehy et al. This is an open access article distributed under the Creative Commons Attribution License, which permits unrestricted use, distribution, and reproduction in any medium, provided the original work is properly cited.

\begin{abstract}
Nylon-6 nanofiber mat incorporated with 5,5-dimethyl hydantoin (DMH) as an antimicrobial drug was electrospun from formic acid. The morphology of the nanofiber mat using scanning electron microscope (SEM) showed that the obtained fiber had an average diameter of around $15-328 \mathrm{~nm}$. The nanofiber was characterized by FTIR spectra, TGA, and DSC. The nanofiber containing drug showed initial fast release. It released about $55 \%$ of its drug content within the first two hours. Moreover, the antimicrobial activity of the electrospun nylon-6 nanofiber containing drug was examined against Escherichia coli, Pseudomonas aeruginosa, Aspergillus niger, and Aspergillus flavus. The nylon-6 nanofiber exhibited high inhibitory effects against the microbes. The results clearly indicate that the antimicrobial activity of the electrospun nylon- 6 nanofiber containing drug varies with the species of the organisms used. Thus, the study ascertains the value of the use of electrospun nanofiber, which could be of considerable interest to the development of new antimicrobial materials. The microbes, examined by SEM, were totally deformed and exhibited severe destruction. Abnormal cell division was observed at high frequencies among cells that tried to divide in the presence of the nanofiber. Many cells were enlarged, elongated, empty ghosts, or fragmented, consistent with the extremely low viability.
\end{abstract}

\section{Introduction}

Electrospinning is widely accepted as a technique to fabricate submicron polymer fibers. Electrospinning is a fiber-forming process, where high voltage is used to create an electrically charged jet of polymer solution or melt from the needle. The polymer solidifies as it travels toward the collecting plate, often producing nanometer scale fibers [1-4]. Nanospider is a modified electrospinning method which requires the use of a high-voltage electrostatic field to create an electrically charged stream of polymer solution or melt. The innovatory idea of the Nanospider is based on the possibility of producing nanofiber from a thin layer of liquid polymer. In this case, Taylor cones (the source of nanofiber) are created on the surface of a rotating roller, immersed'in a polymer solution. Because the Taylor streams are formed next to each other, throughout the entire length of the roller, this revolutionary idea produced many advantages, such as high roductive ability. This commercial method for production of polymeric nanofiber is used in industrial range. This is a simple and versatile method for production of ultrathin fibers from a variety of materials that include polymers. In addition, $\mathrm{Na}-$ nospider has the ability to process a wide range of polymers in diameters of 50-300 nm into nonwoven webs [5].

Generally, polymer-based drug delivery systems are used to optimize the therapeutic properties of drugs and to render them safer, effective, and reliable [6-8]. In addition, the use of antimicrobial polymers offers promise for enhancing 


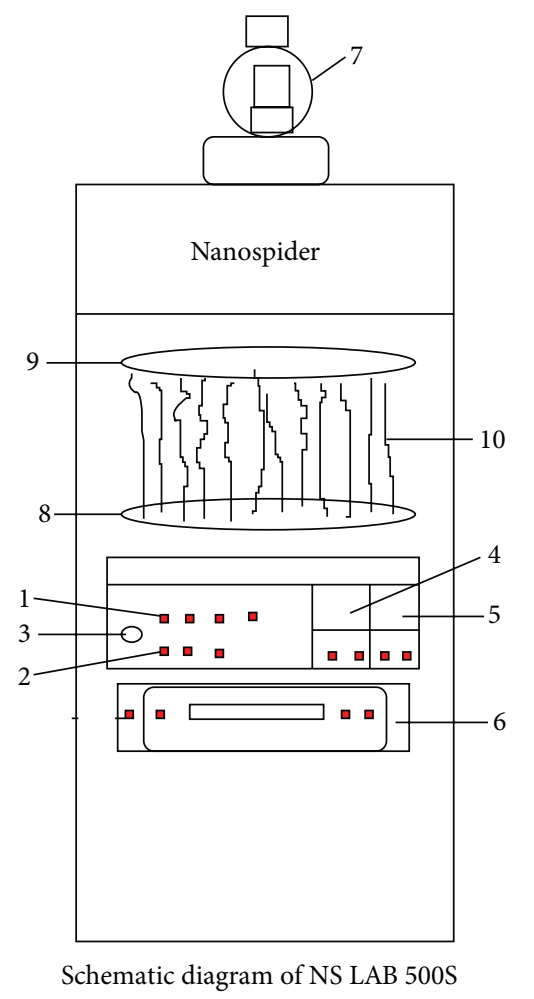

1: Start

2: Stop

3: Emergency

4: Fabric speed

5: Electrode spin

6: Power supply

7: Vacuum

8: Active electrode

9: Collecting electrode

10: Fibers

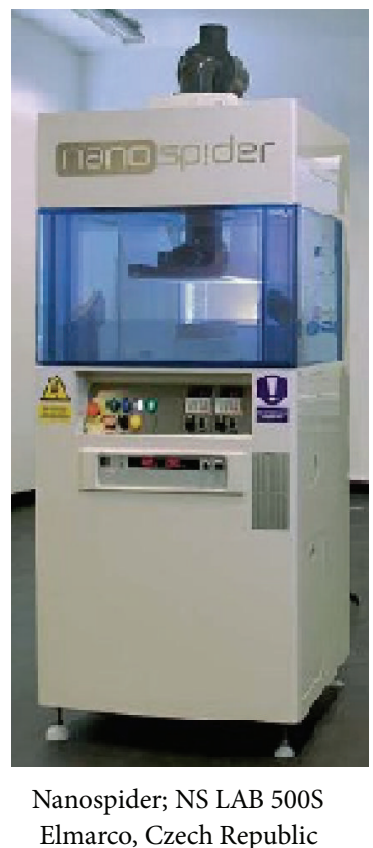

FIGURE 1: Schematic diagram and photograph of electrospinning setup (NS LAB 500S, Elmarco).

the efficacy of some existing antimicrobial agents and minimizing the environmental problems accompanying conventional antimicrobial agents by reducing the residual toxicity of the agents, increasing their efficiency and selectivity, and prolonging the lifetime of the antimicrobial agents [9-11]. Recently, electrospun fibers were explored as new device for drug delivery [12]. The main advantages of the fibrous carriers are that they offer site-specific delivery of drugs to the body. Also, more than one drug can be encapsulated directly into the fibers. Due to the high surface area and porous structure of the electrospun fibers, they have applications in many fields such as medicine [12-17], biosensors [18, 19], sensitized solar cells [20], tissue engineering [21], photonics [22], nanocomposites [23], catalysts [24], and antimicrobial materials and membranes [25].

The focus of this paper is the encapsulation of 5,5dimethyl hydantoin as an antimicrobial drug into electrospun nylon-6 nanofiber using Nanospider technology as a modified electrospinning method. In vitro studies, the antimicrobial activity and the release of the drug were carried out.

\section{Experimental}

2.1. Materials. Polyamide-6 (Ultramid B24 N 03) was purchased from BASF. 5,5-dimethyl hydantoin (DMH) was purchased from Acros. Buffer tablets ( $\mathrm{pH}$ 7.0) were purchased from WINLAB, and buffer solution ( $\mathrm{pH}$ 7.0) was prepared by dissolving buffer tablets in $100 \mathrm{~mL}$ deionized water. All materials and solvents were used as received without further purification.

\subsection{Instrumentation}

2.2.1. Electrospinning Setup. Electrospinning was carried out using Nanospider technology as a modified electrospinning technique, Nanospider laboratory machine NS LAB 500 S from Elmarco s.r.o (Figure 1).

2.2.2. Scanning Electron Microscope (SEM). The morphology of electrospun nanofiber was examined using scanning electron microscopy (SEM), AMRAY Model 1820 Scanning Electron Microscope, UK.

2.2.3. UV-Vis Spectrophotometer. UV spectrophotometer was used to follow up the release of the drug from electrospun nanofiber. It was recorded using PerkinElmer Lambda $35 \mathrm{UV}$-Vis Spectrophotometer.

2.2.4. Thermogravimetric Analysis (TGA). Thermal properties of electrospun nanofibers were examined through using thermogravimetric analysis (TGA), which was carried on TA-Q500 System of TA. Samples of 5-10 mg were heated in the temperature range $30-800^{\circ} \mathrm{C}$ at a scanning rate of $10^{\circ} \mathrm{C} \cdot \mathrm{min}^{-1}$ under nitrogen atmosphere. 
2.2.5. FT-IR Spectroscopy. Fourier-transform infrared (FTIR) spectra were recorded to study the encapsulation of the drug into electrospun nanofiber using TENSOR 27, Bruker.

2.3. Electrospinning of Polyamide-6 Nanofiber. Preparation of nylon-6 nanofiber containing 5,5-dimethyl hydantoin (DMH) as an antimicrobial drug can be described as follows: nylon-6 was dissolved in formic acid at $60-70^{\circ} \mathrm{C}$ at a concentration of $12 \mathrm{wt} . \%(\mathrm{~g} / \mathrm{mL})$; 5,5-dimethy hydantoin $(\mathrm{DMH})$ at concentration of $5 \mathrm{wt} . \%(\mathrm{w} / \mathrm{w})$ of polyamide, was melted in small amount of methanol and then was added to nylon- 6 solution. The mixture was stirred for $1-2 \mathrm{hrs}$ at room temperature prior to electrospinning and was then electrospun at room temperature.

The polymer solution containing the drug DMH was placed in a cylinder containing active electrode parallel to collecting electrode. The polymer solution was delivered under the following conditions: distance from active electrode to collecting electrode is $18 \mathrm{~cm}$ at a driving voltage of $70 \mathrm{kV}$, electrode speed $1.6 \mathrm{r} / \mathrm{min}$, and humidity of $33 \%$. The fibers were collected on an aluminum foil. The electrospun mat was dried in hood at room temperature overnight.

2.4. In Vitro Drug Release Study. The release of 5,5-dimethyl hydantoin (DMH) from the electrospun nylon-6 mat was determined by placing a known mass of the material $(\sim 2 \mathrm{mg})$ in $3 \mathrm{~mL}$ buffer of $\mathrm{pH} 7.0$ at $37^{\circ} \mathrm{C}$. The release of $\mathrm{DMH}$ was monitored by monitoring the absorbance at $\lambda_{\max }=204 \mathrm{~nm}$ as a function of time. Release experiments were done in triplicate.

\subsection{Antimicrobial Assessment}

2.5.1. Organism Strains and Culturing Conditions. Cultures of the following micro-organism were used in the study: Escherichia coli, Pseudomonas aeruginosa, Aspergillus niger, and Aspergillus flavus. These pure cultures were obtained from the Botany and Microbiology Department, College of Science, King and University.

2.5.2. Antifungal Activity. The fungi were subcultured onto Czapek Dox agar (Oxoid). Czapek's Dox agar medium was prepared using $30.0 \mathrm{~g}$ of sucrose, $3.0 \mathrm{~g}$ of $\mathrm{NaNO}_{3}, 0.5 \mathrm{~g}$ of $\mathrm{MgSO}_{4}, 0.1 \mathrm{~g}$ of KCl, $0.01 \mathrm{~g}$ of $\mathrm{FeSO}_{4}, 1.0 \mathrm{~g}$ of $\mathrm{K}_{2} \mathrm{HPO}_{4}$, and $13.0 \mathrm{~g}$ agar in $1.0 \mathrm{~L}$ distilled water in a flask shaken vigorously in an automatic shaker for 20 to $30 \mathrm{~min}$. The medium $\mathrm{pH}$ was adjusted to 7.3 . The media was autoclaved at $121^{\circ} \mathrm{C}$ for $15 \mathrm{~min}$. then poured in Petri dishes. The plates were incubated at room temperature at $25^{\circ} \mathrm{C}$ for 7 days. Growth was assessed every day, and the result expressed in $\mathrm{mm}$ of colony diameter. Electrospun nylon-6 nanofiber containing drug-like discs was placed on agar without fungi as negative control. The antifungal assay plates were incubated at $37^{\circ} \mathrm{C}$ for $0-240 \mathrm{~min}$. The diameters of the inhibition zones were measured in $\mathrm{mm}$.

2.5.3. Antibacterial Activity. An inhibitory test was carried out as described by Rasadah and Muharnad [26] with some modifications: electrospun nylon-6 nanofiber containing drug was tested by the disc diffusion method [27] then put on the surface of the Petri dishes after the growing of fungi. The inhibition zones were estimated after 0-240 min.

Preparation of bacterial inoculums was as follows: the gram-negative Escherichia coli, Pseudomonas aeruginosa were precultured in nutrient broth overnight in a rotary shaker at $37^{\circ} \mathrm{C}$, centrifuged at $10,000 \mathrm{rpm}$ for $5 \mathrm{~min}$, pellet was suspended in distilled water and the cell density was standardized spectrophotometrically $\left(\mathrm{A}_{570} \mathrm{~nm}\right)$. The tested microorganisms were seeded into respective medium by spread plate method $100 \mu \mathrm{L}\left(10^{8}\right.$ cells $\left./ \mathrm{mL}\right)$ with the 24 -hr cultures of bacteria growth in nutrient broth. Electrospun nylon6 nanofiber containing drug-like discs (5 $\mathrm{mm}$ in diameter) were placed on tested organism-seeded plates and on agar without bacteria as negative control. The antibacterial assay plates were incubated at $37^{\circ} \mathrm{C}$ for $4 \mathrm{hrs}$. The diameters of the inhibition zones were measured in $\mathrm{mm}$.

2.5.4. Scanning Electron Micrograph (SEM) of the Used Bacteria and Fungi. Fungal cells were prepared for scanning electron microscopy (SEM) according to the initial fixation and dehydration steps previously published [28]. After the antimicrobial tests, the shape of the cells was examined. The cells were fixed at $24^{\circ} \mathrm{C}$ for 60 min with $2.5 \%$ glutaraldehyde in $0.1 \mathrm{M}$ sodium cacodylate buffer ( $\mathrm{pH}$ 7.2; Sigma-Aldrich Chemie GmbH, Steinheim, Germany), dehydrated with a serial concentration of ethanol, and then dried on a critical point dryer (HCP-2; Hitachi Co.). The dried cell samples were coated with gold and examined using a scanning electron microscope (S-4100; Hitachi Co.). For transmission electron microscopy, dehydrated cells were embedded in a medium type LR white resin (Sigma Chemical Co., St. Louis, $\mathrm{MO}$ ), which was polymerized at $60^{\circ} \mathrm{C}$ for $24 \mathrm{~h}$. Specimens were then viewed with the scanning electron microscope.

\section{Results and Discussion}

3.1. Scanning Electron Microscopy Examination. Electrospun nylon-6 nanofiber containing 5,5-dimethyl hydantoin (DMH) as antimicrobial drug was fabricated using Nanospider technology as a modified electrospinning method. The el-ectrospun mat is opaque due to light scattering from the fibrous structure. The morphology of the obtained electrospun nylon-6 nanofiber containing drug showed that nylon-6 nanofiber have an average diameter of around 15-328 nm (Figure 2). The sheet thickness ranged from 40 to $50 \mu \mathrm{m}$. Also, the fibers obtained had cylindrical morphology and no fiber bundles, indicating that the distance between the active electrode and collecting electrode $18 \mathrm{~cm}$ was adequate for proper evaporation of the solvent.

3.2. FT-IR Spectra. The FT-IR spectra of electrospun nylon6 nanofibers containing drug is presented in (Figure 3 ). The FT-IR spectra showed the absorption band of the DMH at 2927 and $1462,1437 \mathrm{~cm}^{-1}$ represents the stretching vibrations of $\mathrm{C}\left(\mathrm{CH}_{3}\right)_{2}$. The absorption band in the $1723 \mathrm{~cm}^{-1}$ region is characteristic of the stretching vibrations $\mathrm{C}=\mathrm{O}$. 


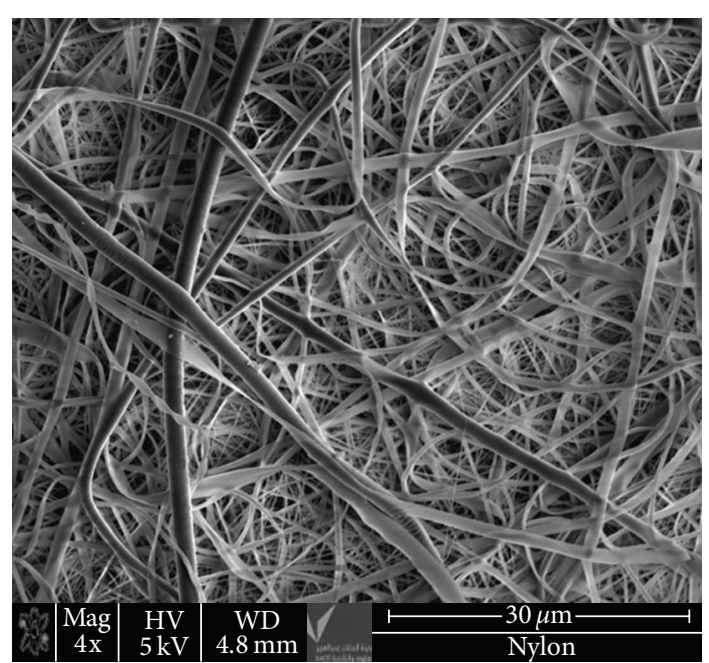

(a)

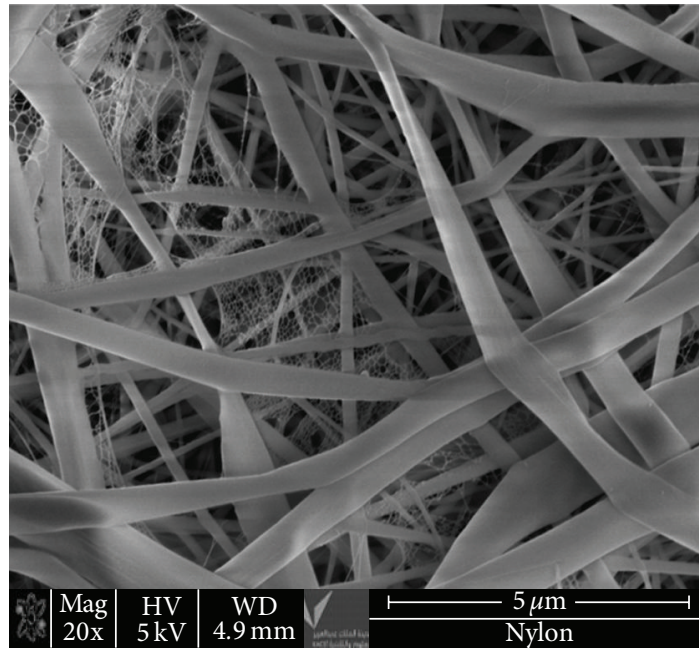

(b)

Figure 2: SEM images of electrospun nylon-6 nanofiber containing 5,5-dimethyl hydantoin (DMH).

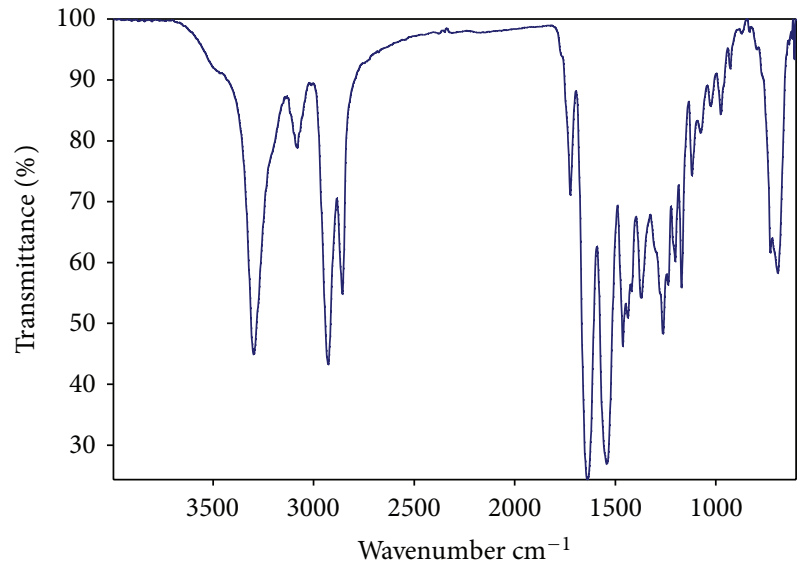

FIGURE 3: FT-IR spectra of electrospun nylon-6 nanofiber containing 5,5-dimethyl hydantoin (DMH).

On the other hand, the absorption intensity at $3297 \mathrm{~cm}^{-1}$ is representing the stretching of the amide group. The absorption band in the $2856 \mathrm{~cm}^{-1}$ region is characteristic of the stretching vibrations $\mathrm{CH}_{2}$ in polyamide backbone. The absorption band in the $1628 \mathrm{~cm}^{-1}$ region is characteristic of the stretching vibrations $\mathrm{C}=\mathrm{O}$ of polyamide. The absorption band in the $1541 \mathrm{~cm}^{-1}$ region is characteristic of the stretching vibrations $\mathrm{NH}$. This data indicated that the encapsulation of DMH in electrospun nylon-6 nanofiber is successful.

\subsection{Thermogravimetric Analysis (TGA) Study. Figure 4 shows} the thermogram of electrospun nylon-6 nanofiber containing drug. It showed that the electrospun nylon-6 nanofiber containing drug was degraded in three steps. The first step represents the evaporation of the residual absorbed water with a weight loss of about $0.5 \%$ at the temperature range of $30-100^{\circ} \mathrm{C}$. The second step with a weight loss of about $3.9 \%$

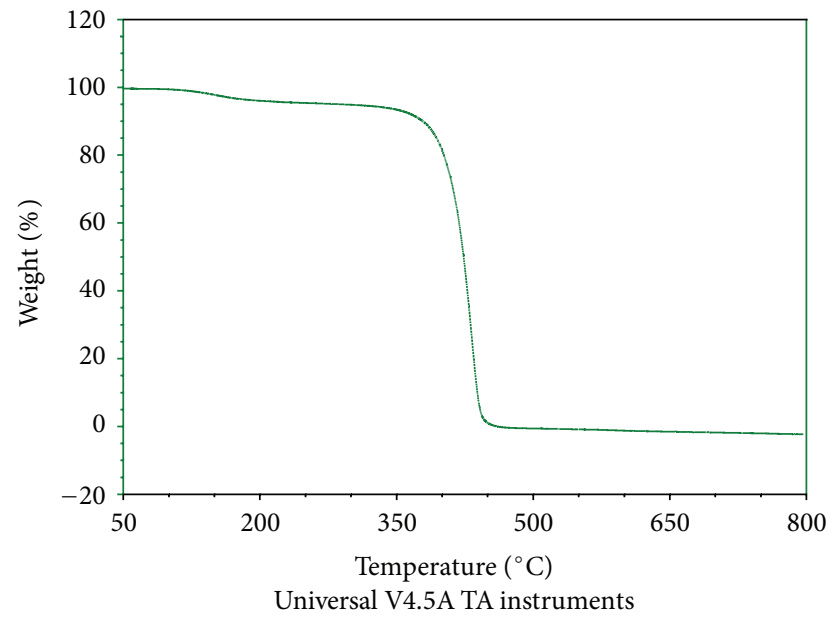

FIGURE 4: TGA curves of electrospun nylon-6 nanofiber containing 5,5-dimethyl hydantoin (DMH). The heating speed was $10^{\circ} \mathrm{C} / \mathrm{min}$.

at the temperature range of $100-200^{\circ} \mathrm{C}$, which represents the degradation of DMH. The third step with a weight loss of about $91.8 \%$ at the temperature range of $200-475^{\circ} \mathrm{C}$, which represents the degradation nylon- 6 . Moreover the $T_{\text {on }}$ for the nylon- 6 was found to be $401{ }^{\circ} \mathrm{C}$, and the mat losses $50 \%$ of its weight at $424^{\circ} \mathrm{C}$ and leaves a residue of $3.4 \%$ at $475^{\circ} \mathrm{C}$.

3.4. In Vitro Drug Release. The electrospinning technique provides a unique and simple technique for the drug delivery. The advantages of this technique are that it could be applied for a wide range of pharmaceutical compounds either functionalized or nonfunctionalized. It could be used for more than one drug at the same time. Also, it is possible to be electrospun as layers. The microphotograph of the electrospun nylon-6 nanofiber containing drug showed 


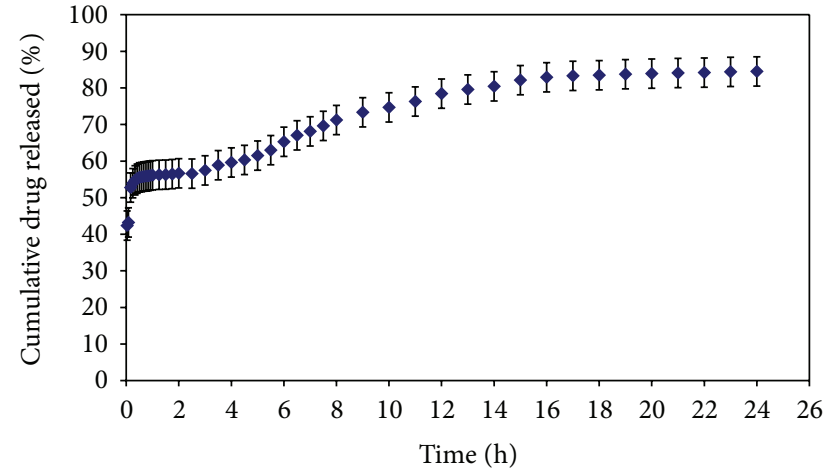

FIGURE 5: Release profiles of 5,5-dimethyl hydantoin (DMH; over $24 \mathrm{hrs}$ ) form electrospun nylon- 6 nanofiber in buffer solution of $\mathrm{pH}$ 7.0 at the body temperature $\left(37^{\circ} \mathrm{C}\right)$.

regular fiber diameter containing DMH entrapped on it. The rate of drug released from electrospun nylon- 6 nanofiber was investigated in buffer solution of $\mathrm{pH} 7.0$ at $37^{\circ} \mathrm{C}$ (body temperature). The release profile of the drug from electrospun nylon-6 nanofiber is shown in (Figure 5). It showed initial fast release. It released about $55 \%$ of its drug content within the first two hours and reached about $84 \%$ of its drug content within 24 hrs.

3.5. Antimicrobial Assessment. Results obtained from the disc method in the present study relieved that the electrospun nylon-6 nanofiber containing drug exhibited potential antibacterial activity against Escherichia coli and Pseudomonas aeruginosa, and antifungal activity against Aspergillus niger and Aspergillus flavus (Figures 6 and 7). When tested by the disc diffusion method, electrospun nylon- 6 nanofiber containing drug showed significant activity against Pseudomonas aeruginosa after $120 \mathrm{~min}(4 \mathrm{~mm})$ followed by Escherichia coli after $240 \mathrm{~min}(3 \mathrm{~mm})$, then Aspergillus niger after 60 minutes $(3 \mathrm{~mm})$ and Aspergillus flavus after $180 \mathrm{~min}(3 \mathrm{~mm})$.

3.6. Scanning Electron Micrograph (SEM) of the Bacteria. The effect of the electrospun nylon-6 nanofiber containing drug on Aspergillus niger and Aspergillus flavus caused pronounced deformation and visible shrinkage in fungal strains studied (Figure 8). The most important result was a considerable reduction of wrinkling and deformation of the fungal cells. On the other hand, Aspergillus niger and Aspergillus flavus cells were observed in damaged pellets and somewhat resembled pseudohyphae that were highly irregular and aborted.

Moreover, the Escherichia coli and Pseudomonas aeruginosa cells examined using SEM were totally deformed and exhibited severe destruction. The surfaces of the bacterial cells were damaged and had become rough and swollen, but unlisted (Figure 9). In contrast, it was found that intact cells of Aspergillus niger and Aspergillus flavus had smooth surfaces with overall intact morphology. It was observed that the structure of the cell wall surface layer was wrinkled, and round pores were partially deformed, indicating that

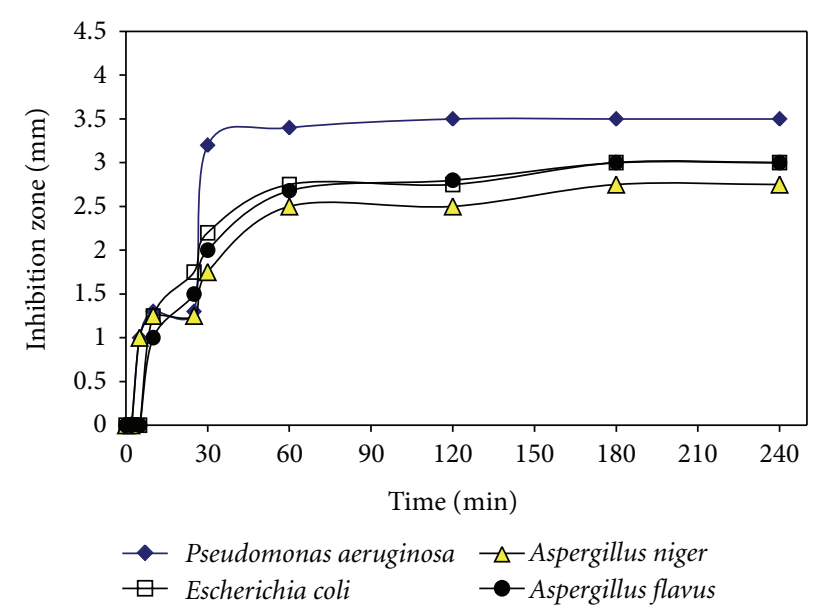

FIGURE 6: Inhibition zone ( $\mathrm{mm}$ ) of electrospun nylon-6 nanofiber containing drug against bacteria and fungi.

the cytoplasmic structures were flushed out of the cells. Abnormal cell division was observed at high frequencies among cells that tried to divide in the presence of the polymer. Many cells were enlarged, elongated, empty ghosts, or fragmented, consistent with the extremely low viability. The effect was investigated and compared with the control cells. This malformation in bacterial and fungal cells may be due to inhibition of cell wall synthesis, inhibition of protein synthesis, inhibition of nucleic acid synthesis, inhibition of metabolic pathways, and interference with cell membrane integrity $[29,30]$.

These results clearly indicate that the antibacterial and antifungal activity of the electrospun nylon-6 nanofiber containing drug varies with the species of the organisms used. In fact, the emergence, in recent years, of strains of microorganisms that are resistant to commonly used antibiotics has stimulated a search for new naturally occurring bacterial agents that may have clinical utility. There is a lot of effort to try to use antimicrobial peptides for therapeutics. This is because bacterial resistance to conventional antibiotics has become a major problem worldwide due to their extensive use. Thus, the study ascertains the value of the used of the electrospun nylon-6 nanofiber containing drug which could be of considerable interest to the development of new antimicrobial materials.

\section{Conclusion}

Nylon electrospun nylon-6 nanofiber containing 5,5dimethyl hydantoin (DMH) as an antimicrobial drug, with diameter of $15-328 \mathrm{~nm}$, was successfully fabricated from formic acid using Nanospider technology. The antimicrobial activity of nylon electrospun nylon-6 nanofiber containing drug was examined. The results clearly indicate that the antimicrobial activity of electrospun nanofiber vary with the species of the tested organisms. Thus, the study ascertains the value of the use of nylon electrospun fibers which could be of considerable interest to the development of new 
(1)

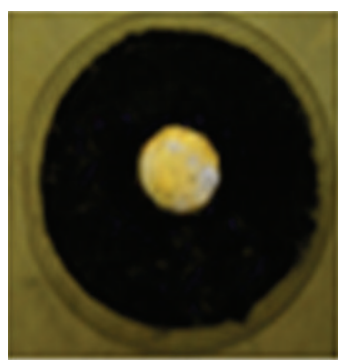

(Time zero)

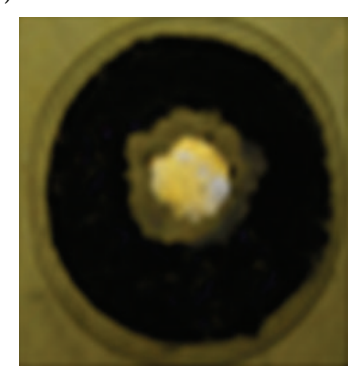

(After 4 hrs)
(Control)

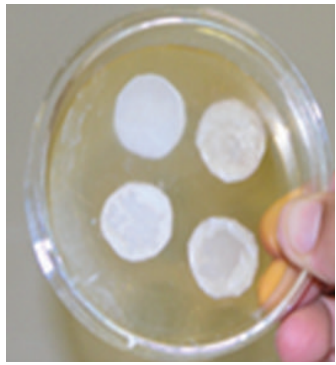

(2)

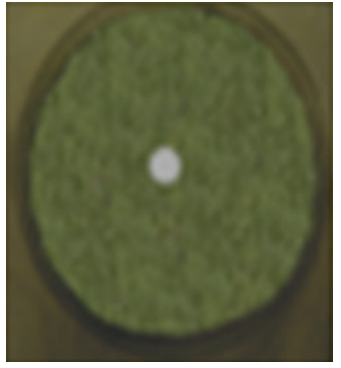

(Time zero)

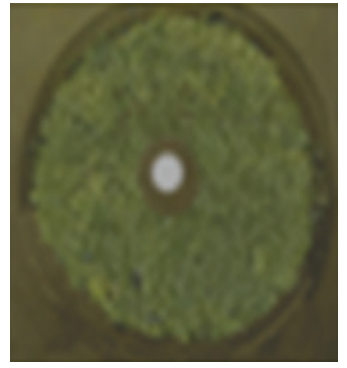

(After 4 hrs)
(A)

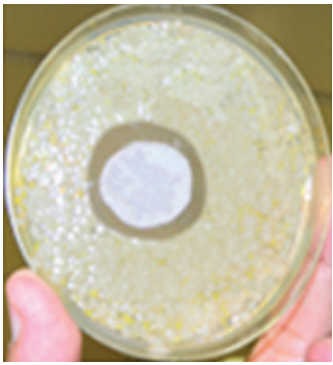

(B)

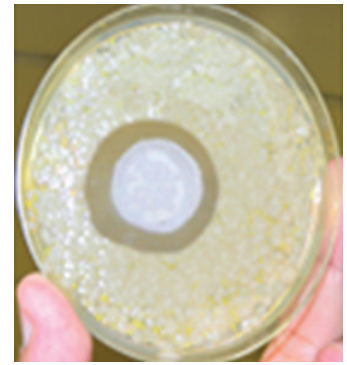

FIGURE 7: Inhibition zones of the electrospun nylon-6 nanofiber containing drug against two pathogenic fungi: (1) Aspergillus niger and (2) Aspergillus flavus and two pathogenic bacteria; (A) Escherichia coli, (B) Pseudomonas aeruginosa, and (Control) negative control.

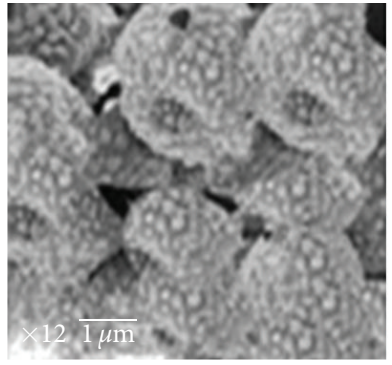

Intact fungi

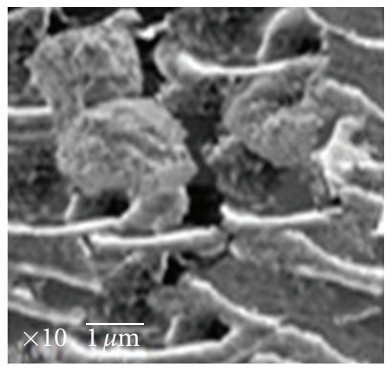

(a) Aspergillus niger

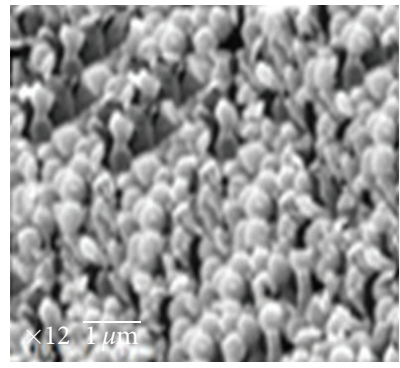

Intact fungi

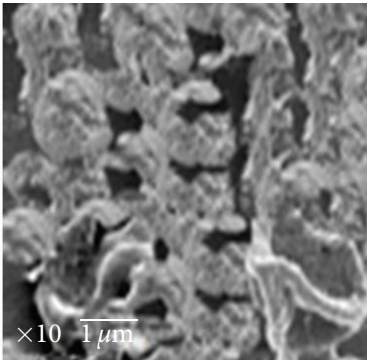

(b) Aspergillus flavus

FIGURE 8: Scanning electron micrograph (SEM) of antifungal activity of the electrospun nylon-6 nanofiber containing drug against Aspergillus niger and Aspergillus flavus.

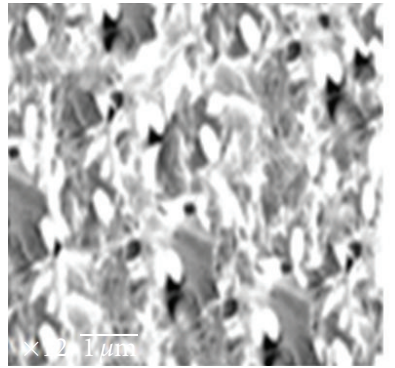

Intact bacteria

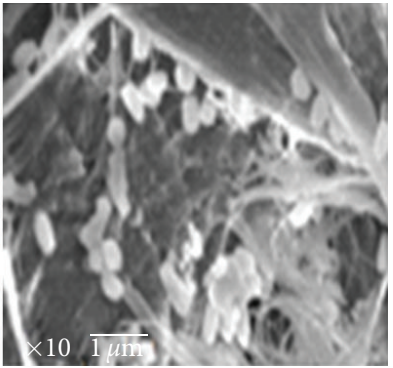

$\times 1 0 \longdiv { 1 \mu \mathrm { i } }$

(c) Pseudomonas aeruginosa
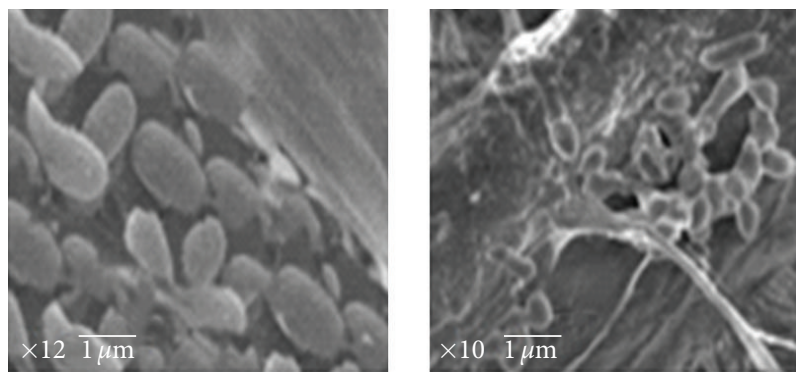

Intact bacteria

(d) Escherichia coli

FIGURE 9: Scanning electron micrograph (SEM) of antibacterial activity of the electrospun nylon-6 nanofiber containing drug against Pseudomonas aeruginosa and Escherichia coli. 
antimicrobial materials. The obtained nylon- 6 nanofiber is promising for wound-healing applications.

\section{Acknowledgment}

The authors extend their appreciation to the Deanship of Scientific Research at King Saud University for funding the paper through the Research Group Project no. RGP-VPP021.

\section{References}

[1] S. Zhang, W. S. Shim, and J. Kim, "Design of ultra-fine nonwovens via electrospinning of Nylon 6: spinning parameters and filtration efficiency," Materials and Design, vol. 30, no. 9, pp. 3659-3666, 2009.

[2] A. Pedicini and R. J. Farris, "Thermally induced color change in electrospun fiber mats," Journal of Polymer Science, Part B, vol. 42, no. 5, pp. 752-757, 2004.

[3] J. M. Deitzel, W. Kosik, S. H. McKnight, N. C. Beck Tan, J. M. DeSimone, and S. Crette, "Electrospinning of polymer nanofibers with specific surface chemistry," Polymer, vol. 43, no. 3, pp. 1025-1029, 2001.

[4] R. Nirmala, R. Navamathavan, M. H. El-Newehy, and H. Y. Kim, "Preparation and electrical characterization of polyamide-6/chitosan composite nanofibers via electrospinning," Materials Letters, vol. 65, no. 3, pp. 493-496, 2011.

[5] Z. Rożek, W. Kaczorowski, D. Lukáš, P. Louda, and S. Mitura, "Potential applications of nanofiber textile covered by carbon coatings," Journal of Achievements in Materials and Manufacturing Engineering, vol. 27, no. 1, pp. 35-38, 2008.

[6] E. R. Kenawy, F. I. Abdel-Hay, M. H. El-Newehy, and G. E. Wnek, "Controlled release of ketoprofen from electrospun poly(vinyl alcohol) nanofibers," Materials Science and Engineering A, vol. 459, no. 1-2, pp. 390-396, 2007.

[7] E. R. Kenawy, M. H. El-Newehy, and S. S. Al-Deyab, "Controlled release of atenolol from freeze/thawed poly(vinyl alcohol) hydrogel," Journal of Saudi Chemical Society, vol. 14, no. 2, pp. 237-240, 2010.

[8] E. R. Kenawy, S. Al-Deyab, and M. H. El-Newehy, "Controlled release of 5-Aminosalicylic acid (5-asa) from new biodegradable polyurethanes," Molecules, vol. 15, no. 4, pp. 2257-2268, 2010.

[9] E. R. Kenawy, F. I. Abdel-Hay, L. Shahada, A. E. R. R. El-Shanshoury, and M. H. El-Newehy, "Biologically active polymers. IV. Synthesis and antimicrobial activity of tartaric acid polyamides," Journal of Applied Polymer Science, vol. 102, no. 5, pp. 4780-4790, 2006.

[10] E. R. Kenawy, F. I. Abdel-Hay, A. E. R. R. El-Shanshoury, and M. H. El-Newehy, "Biologically active polymers. V. Synthesis and antimicrobial activity of modified poly(glycidyl methacrylate-co-2-hydroxyethyl methacrylate) derivatives with quaternary ammonium and phosphonium salts," Journal of Polymer Science, Part A, vol. 40, no. 14, pp. 2384-2393, 2002.

[11] E. R. Kenawy, F. I. Abdel-Hay, A. E. R. R. El-Shanshoury, and M. H. El-Newehy, "Biologically active polymers: synthesis and antimicrobial activity of modified glycidyl methacrylate polymers having a quaternary ammonium and phosphonium groups," Journal of Controlled Release, vol. 50, no. 1-3, pp. 145$152,1998$.
[12] E. R. Kenawy, F. I. Abdel-Hay, M. H. El-Newehy, and G. E. Wnek, "Processing of polymer nanofibers through electrospinning as drug delivery systems," Materials Chemistry and Physics, vol. 113, no. 1, pp. 296-302, 2009.

[13] C. L. He, Z. M. Huang, X. J. Han, L. Liu, H. S. Zhang, and L. S. Chen, "Coaxial electrospun poly(L-lactic acid) ultrafine fibers for sustained drug delivery," Journal of Macromolecular Science, Part B, vol. 45, no. 4, pp. 515-524, 2006.

[14] P. Taepaiboon, U. Rungsardthong, and P. Supaphol, "Drugloaded electrospun mats of poly(vinyl alcohol) fibres and their release characteristics of four model drugs," Nanotechnology, vol. 17, no. 9, pp. 2317-2329, 2006.

[15] W. Cui, X. Li, X. Zhu, G. Yu, S. Zhou, and J. Weng, "Investigation of drug release and matrix degradation of electrospun poly(DL-lactide) fibers with paracetanol inoculation," Biomacromolecules, vol. 7, no. 5, pp. 1623-1629, 2006.

[16] E. Luong-Van, L. Grøndahl, K. N. Chua, K. W. Leong, V. Nurcombe, and S. M. Cool, "Controlled release of heparin from poly( $\varepsilon$-caprolactone) electrospun fibers," Biomaterials, vol. 27, no. 9, pp. 2042-2050, 2006.

[17] H. Jiang, Y. Hu, Y. Li, P. Zhao, K. Zhu, and W. Chen, "A facile technique to prepare biodegradable coaxial electrospun nanofibers for controlled release of bioactive agents," Journal of Controlled Release, vol. 108, no. 2-3, pp. 237-243, 2005.

[18] D. Li, M. W. Frey, and A. J. Baeumner, "Electrospun polylactic acid nanofiber membranes as substrates for biosensor assemblies," Journal of Membrane Science, vol. 279, no. 1-2, pp. 354363, 2006.

[19] A. C. Patel, S. Li, J. M. Yuan, and Y. Wei, "In situ encapsulation of horseradish peroxidase in electrospun porous silica fibers for potential biosensor applications," Nano Letters, vol. 6, no. 5, pp. 1042-1046, 2006.

[20] Y. Zhao, J. Zhai, S. Tan, L. Wang, L. Jiang, and D. Zhu, "TiO, micro/nano-composite structured electrodes for quasi-solidstate dye-sensitized solar cells," Nanotechnology, vol. 17, no. 9, pp. 2090-2097, 2006.

[21] P. Wutticharoenmongkol, N. Sanchavanakit, P. Pavasant, and P. Supaphol, "Preparation and characterization of novel bone scaffolds based on electrospun polycaprolactone fibers filled with nanoparticles," Macromolecular Bioscience, vol. 6, no. 1, pp. 70-77, 2006.

[22] T. A. Telemeco, C. Ayres, G. L. Bowlin et al., "Regulation of cellular infiltration into tissue engineering scaffolds composed of submicron diameter fibrils produced by electrospinning," Acta Biomaterialia, vol. 1, no. 4, pp. 377-385, 2005.

[23] N. Tomczak, N. F. Van Hulst, and G. J. Vancso, "Beaded electrospun fibers for photonic applications," Macromolecules, vol. 38, no. 18, pp. 7863-7866, 2005.

[24] Y. H. Lee, J. H. Lee, I. G. An et al., "Electrospun dualporosity structure and biodegradation morphology of Montmorillonite reinforced PLLA nanocomposite scaffolds," Biomaterials, vol. 26, no. 16, pp. 3165-3172, 2005.

[25] R. Dersch, M. Steinhart, U. Boudriot, A. Greiner, and J. H. Wendorff, "Nanoprocessing of polymers: applications in medicine, sensors, catalysis, photonics," Polymers for Advanced Technologies, vol. 16, no. 2-3, pp. 276-282, 2005.

[26] M. A. Rasadah and Z. Muharnad, Prosid. Perubatan Tradisional Malaysia Ke-5, vol. 173, Universiti Malaya, 1988.

[27] Anonymous, Pharmacopiea of India (The Indian Pharmacopiea), Government of India, Ministry of Health and Family Welfare, New Delhi, India, 3rd edition, 1996. 
[28] C. W. Moore, R. D. Valle, J. M. Koy, A. Pramanik, and R. E. Gordon, "Lesions and preferential initial localization of [S-methyl- ${ }^{3} \mathrm{H}$ ] bleomycin $\mathrm{A}_{2}$ on Saccharomyces cerevisiae cell walls and membranes," Antimicrobial Agents and Chemotherapy, vol. 36, no. 11, pp. 2497-2505, 1992.

[29] F. C. Tenover, "Mechanisms of Antimicrobial Resistance in Bacteria," American Journal of Medicine, vol. 119, no. 6, pp. S3S10, 2006.

[30] E. Hart, K. Azzopardi, H. Taing et al., "Efficacy of antimicrobial polymer coatings in an animal model of bacterial infection associated with foreign body implants," The Journal of Antimicrobial Chemotherapy, vol. 65, no. 5, pp. 974-980, 2010. 

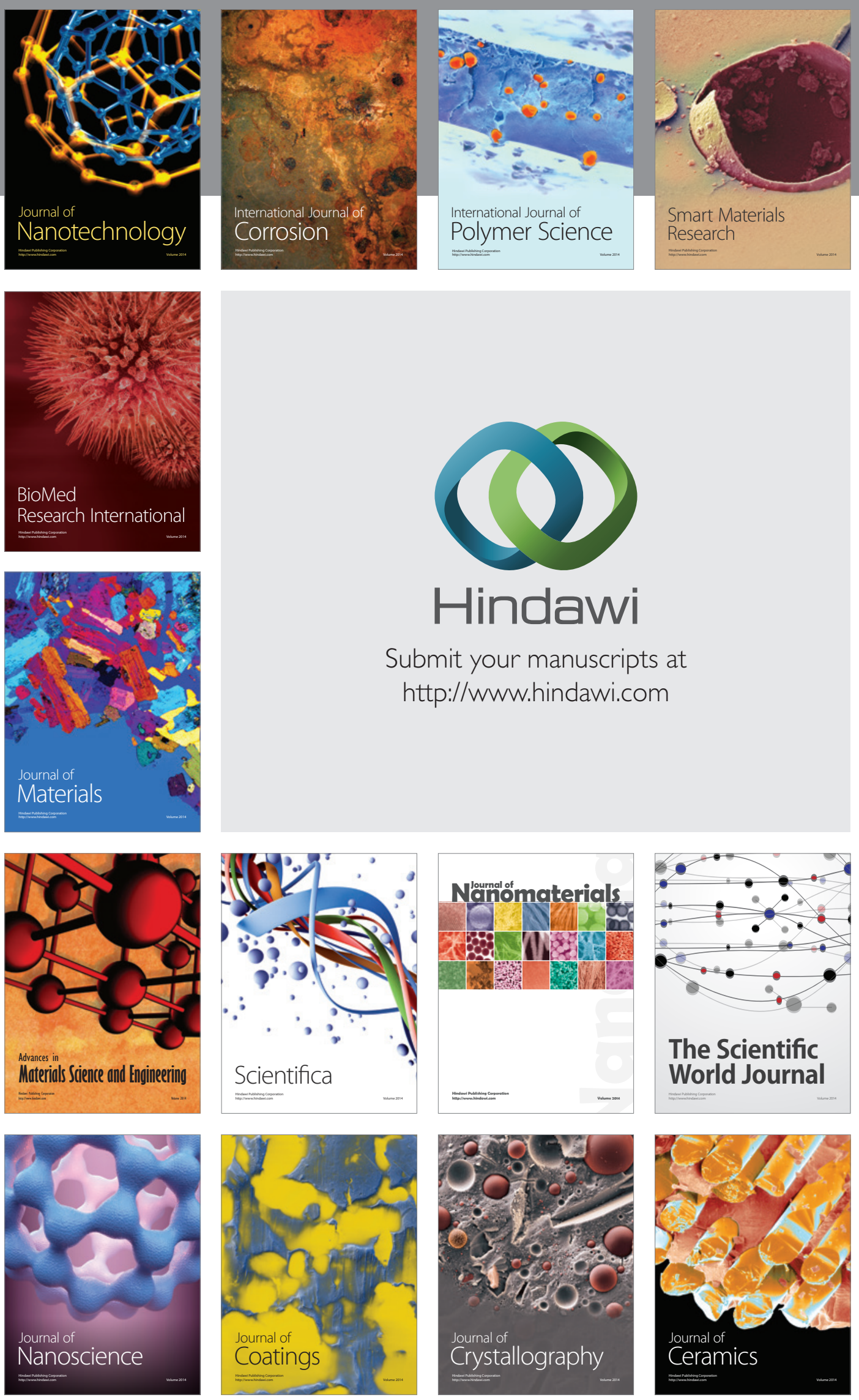

The Scientific World Journal

Submit your manuscripts at

http://www.hindawi.com

\section{World Journal}

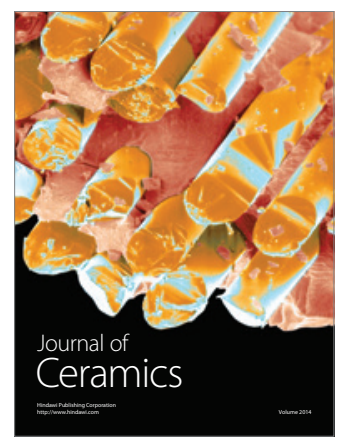

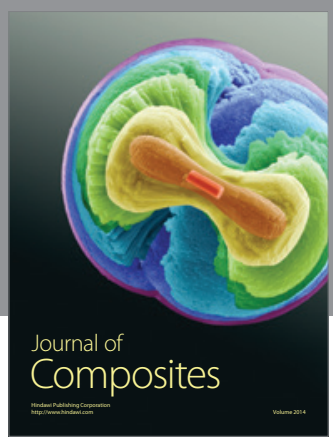
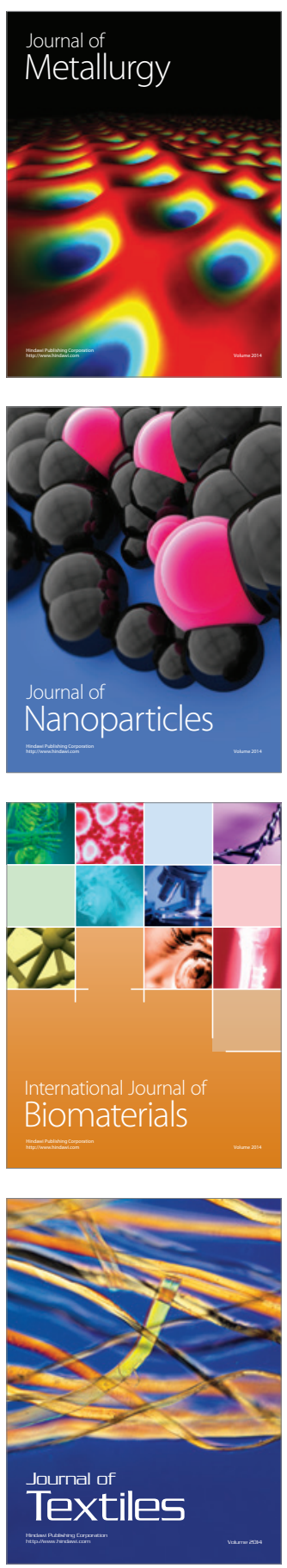